multiple bone fractures - 56, bone fractures + visceral trauma 24. 44 children had open bone fractures or fractures accompained with vast defects of soft tissues. Operative interventions in polytrauma are divided into urgent, elective and delayded. Urgent intervention (according to vital indications) are conducted together with anti-shock therapy in massive blood losses (injury of spleen, liver), crushing of lungs, cardiac tamponade, intracranial compression. Elective interventions are prformed after stabilization of patient's state and after bringing him out of shock.

Results: Sets for external fixation were used in acute period of trauma, in early and late posttraumatic period. Tipe of sets depended on character of injury and followed steps of treatment. Indications for external fixation in acute period and catabolic phase of traumatic disease were: 1. multiple fragmental fractures, 2. defects of bones, 3. vast defects of soft tissues, 4. long bone fractures accompained with severe brain trauma. Indications for external fixation in late period were mulunion, in postpond ununion, deformations and shortening of extremities.

Conclusion: The usage of external fixation was an effective approach in treatment of children with severe complicated injuries of extremities. Advantages of external fixation in conditions of polytrauma were undiscutable: management in force effects, absence of secondary dislocations, good conditions for debridment and follow restorative treatment, mobility of patients.

Prehosp Disaster Med 2011;26(Suppl. 1):s36-s37 doi:10.1017/S1049023X11001312

\section{(A131) Surgical Help to Children in Disasters and Wars L. Roshal}

Institute of Emergency Children's Surgery and Trauma, Moscow, Russian Federation

Purpose: To describe results of experience in providing surgical aid to children in technological and natural disasters in various countries of the world: Haiti, Algeria, Armenia, Afganistan (three times), Georgia, Egypt, Russia, Indonesia (twice), Iran, Pakistan, India, Japan, Gaza strip, Chechnya, and Yugoslavia.

Materials and Methods: The Russian specialized team consisting of highly qualified pediatric specialists (traumatologists, neurosurgeons, plastic surgeons, specialists in wound treatment, anaesthesiologists-reanimatologists and others if necessary) work at local hospitals in the disaster zone. All of them work as volunteers. The most serious pediatric victims were concentrated in one or two regional hospitals. The volunteer specialists work on a twenty-four hour basis together with local doctors. Every day they examine patients, control wound bandaging, and perform surgeries. For long tubular bone fractures metalosteosynthesis is used. Modern techniques are used for Crush syndrome and for extended and purulent wounds (water-based ointments, early autoplasty). Currently, the main difficulty in many cases is primary treatment of extensive wounds with their complete closure and the many indications for amputations. Conservative and sparing techniques are not often used.

Conclusions: Pediatric victims in technologic and natural disasters must be helped by pediatric specialists. Our experience in the countries to which we have responded have revealed that there are not enough local specialists who can provide highly professional aid to children. There is no known coordinating structure in the world to efficiently organize specialized pediatric help to children in disasters and wars.

Prehosp Disaster Med 2011;26(Suppl. 1):s37

doi:10.1017/S1049023X11001324

\section{(A132) Animals and Refugees}

G.V. Vroegindewey

Center for Public and Corporate Veterinary Medicine, College Park, Maryland, United States of America

Disasters caused by natural and human-made hazards often result in mass-movement of populations. Within these movements, companion and production animals can have significant impacts on the internally displaced persons, refugees, and disaster managers. The humanitarian agency Sphere recently identified and highlighted the fact that animal welfare and protecting the livestock of rural communities (before and after disasters) is crucial to the survival of those disaster-impacted communities. Those who are faced with the decision to move will consider the impact and risk/benefit evaluation of housing, losing companion animals, or the loss of production animals necessary for food security and economic survival. Animal impacts also include the potential to spread zoonotic or animal transboundary diseases, raise security concerns within camps, loss of future breeding stock, feeding, housing, and maintaining accountability. Issues involved with animals and refugees in the evacuation decision process, during movement, and in ad hoc, developing, and mature refugee camps will be discussed.

Prehosp Disaster Med 2011;26(Suppl. 1):s37 doi:10.1017/S1049023X11001336

(A133) Emergency Response and Vulnerable Older People: Some Keys for Better Practices D. Maltais, T. Maala

Sciences Humaines, Chicoutimi, Canada

Emergency response and vulnerable older people: some keys for better practices Danielle Maltais, Ph.D. professor and Taha-Abderrafie Maala, M.Sc student, Social Work Teaching Unit, Department of Human Sciences, University of Quebec in Chicoutimi (UQAC). In the event of a natural or technological disaster, certain groups of people, some of elderly, are more vulnerable than others because they do not have easy access to the community resources. For example, several older people, especially those with a physical or cognitive incapacity and those with a low income, do not generally have a car available which can hinder their evacuation during a flood, an earthquake or a hurricane. Moreover, several elders live in older buildings not built to resist to shocks of all kinds. Older people, particularly those with a physical or cognitive incapacity, those with a low income or those without a social network belong to groups at risk to undergo wounds, to die or develop post-disaster health problems. Considering this, several researchers and national or international government and private as well as non-profit organizations such as World Health Organization, the International Red Cross or HelpAge International produced several guides on intervention aiming to support workers caring for the elderly during a disaster. The purpose of this communication is to present the main outstanding facts and recommendations of these various documents in order to heighten the participants' awareness 
of the importance to take into account the specificities of older people during the application of emergency measures and the recovery period of a community.

Prehosp Disaster Med 2011;26(Suppl. 1):s37-s38

doi:10.1017/S1049023X11001348

(A134) Special Needs of the Elderly During Disasters Suggested Strategies and Lessons Learned from the 2007 Tulsa, Oklahoma Ice Storm

J. Gulden, ${ }^{1}$ M.K. Stewart, ${ }^{2}$ C.E. Stewart ${ }^{2}$

1. Emergency Management Support, M5G2V1, Canada

2. Department of Emergency Medicine, 74137, United States of America

Special Needs of the Elderly During Disasters Suggested Strategies and Lessons Learned from the 2007 Tulsa, Oklahoma Ice Storm. On the evening of December 7, 2007 an ice storm occurred in the south central United States causing severe power outages in Tulsa, Oklahoma. In Oklahoma alone, 900,000 people were without power for periods of up to 3 weeks. Approximately $13.2 \%$ of the population in Oklahoma aged 65 + live in institutional care (2000 US Census Report). There are 498 nursing home facilities in Oklahoma serving this majority of this population (a small percentage live in other types of care facilities). Of these facilities 143 lost electrical power for up to six days, 88 lost power but had generators available within 24 hours or less, and 55 had no alternative source of power. Of the 55 without power, 42 relocated residents. Critical infrastructure failures during natural disasters can create a cascade of direct and indirect losses due to a number of physical, social and economic interdependencies that exist (Rinaldi, Peerenboom \& Kelly 2001). The elderly present some unique characteristics that make them more vulnerable during natural disasters. Chronic health problems, physical mobility and cognitive limitations make them unable to adequately prepare for disasters (Aldrich \& Benson 2008) making them entirely dependent on the facilities. In the three years since the storm the Oklahoma Disaster Institute has focused its efforts on developing and implementing mitigation strategies to address power loss in nursing homes. These strategies included discussions with the Department of Health, Emergency Medical Services Authority and local hospital officials. As a result of these discussions, table-top exercises were conducted in multiple venues, and speakers from the Department of Health, EMSA, and emergency management were arranged in an Extended Care Facility Workshop. This paper will look at lessons learned, mitigation strategies and successes in protecting the elderly in nursing homes during natural disasters.

Prehosp Disaster Med 2011;26(Suppl. 1):s38

doi:10.1017/S1049023X1100135X

(A135) Preliminary Results of Post-Flooding Impacts on Rural Elderly in Hainan Province, China

E.Y.Y. Chan, ${ }^{1}$ C.L.Y. Lin ${ }^{1}$ P.P.Y. Lee, ${ }^{1}$ I. Zheng, ${ }^{2}$

E.Y.L. Cheung, ${ }^{1}$ S.C. Lam ${ }^{2}$

1. CCOC, School of Public Health and Primary Care, NT, Hong Kong

2. Department of Ophthalmology and Visual Science, Hong Kong, Hong Kong

Background: Limited information is available on the health outcomes of the rural older population in developing countries is affected by disasters. In October 2010, Hainan Province experienced severe flooding following heavy rains. Nearly four million people were affected and many had undergone resettlement. This study investigated the impacts of the flooding on people living in the disaster-affected rural communities. The findings were compared with baseline information collected in 2010 about health issues in rural villages in Hainan. Health outcome comparisons also were made between ethnic groups (Han versus $\mathrm{Li}$ ).

Methods: A two-stage cluster-sampling, cross-sectional postdisaster study was conducted. The entire Hainan Island was categorized into ranks of different severity in rainfall amount and associated damage in October (most severe, intermediate, least severe). The county with the most rainfall and the most severe ranking and the one with least rainfall and the least severe ranking were identified. In each county, one Han and one Li village were chosen by using a computer-generated random number, so four villages were sampled in total. More than 100 individuals $\geq 50$ years of age were interviewed by face-to-face survey. Data on disaster-related injuries, socio-demographic information, non-communicable disease, lifestyle, and mental health were collected.

Results: Findings indicated the severity of impact was associated with self-reported health outcomes of older population. Gender and ethnic differences were found in reported health outcomes. Predictors of adverse post-disaster health outcomes in older populations in rural communities were identified.

Conclusions: The results demonstrated significant differences in the impacts of flooding in rural populations. Targeted services and interventions should be planned to address the disparity and meet the physical and mental health needs post-disaster.

Prehosp Disaster Med 2011;26(Suppl. 1):s38

doi:10.1017/S1049023X11001361

\section{(A136) Eldery in Emergency}

M.C. Saenz

Pshycological Support, Lomas de Zamora, Argentina

Elderly in emergency - Presentation: Psychosocial support is essential to prevent mental health disorders in the elders subjected to trauma in emergencies that induces to isolation as well as risks or vulnerability for them and their environment. Financial crisis, natural disasters, attacks, poverty, violence and loneliness in the social environment turn threatening for them. Reality becomes hard and produces disorganization in mental health.

Objectives: Elder people who have gone through one or more of the following situations are the ones who are prone to develop intense or immediate character disorder. With strategies that increase the existing psychosocial protection factors stress at different intervention levels is lowered. Those who have gone through one or more violent experiences are the ones who are prone to develop intense or immediate character disorder. Cultural transferring (between adults and between adults and children) and mutual help between adults and children is held. Methodology: Cognitive processing factors associated to each individual's anxiety: stress, depression, loneliness, panic attacks etc. Some techniques have been developed to understand emotions and learn how to manage them: songs, classic tales, puppets, advertisements and anagrams, Kessen cards, etc. All the material and the results were evaluated with clinic tests and professional help. 